\title{
The effect of $\mathrm{HCl}$ treatment on water vapor adsorption characteristics of clinoptilolite rich natural zeolite
}

\author{
Fehime Cakicioglu-Ozkan *, Semra Ulku \\ Chemical Engineering Department, Engineering Faculty, Izmir Institute of Technology, Gulbahce Koyu, 35430 Urla, İzmir, Turkey
}

Received 22 March 2004; received in revised form 7 August 2004; accepted 13 August 2004

Available online 30 October 2004

\begin{abstract}
In this study, water vapor adsorption properties of the clinoptilolite rich zeolite tuff, from Bigadic (Turkey), and its modified forms were examined. The modified forms were obtained by treating the tuff with $\mathrm{HCl}$ solutions $(0.032,0.16,0.32,1.6$ or $5 \mathrm{M})$ at $25,40,75$ and $100{ }^{\circ} \mathrm{C}$ for $3 \mathrm{~h}$. Infrared spectroscopy and water vapor adsorption were used for the characterization of the zeolites. Langmuir, BET and Dubinin-Raduschevich methods were applied in the analysis of water vapor adsorption data. Applications of Dubinin Raduschevich equation to the water adsorption data displayed that the super-micropore volume was not very sensitive to acid treatment. It was found out that the Langmuir surface area and ultra-micropore volume depend on the degree of the removal of aluminum from the structure.
\end{abstract}

(C) 2004 Elsevier Inc. All rights reserved.

Keywords: Clinoptilolite; Water vapor; Adsorption; Acid treatment; Dealumination

\section{Introduction}

Zeolites are crystalline, hydrated alumina silicates of group 1 and 2 elements, consisting of $\mathrm{SiO}_{4}$ and $\mathrm{AlO}_{4}$ tetrahedra linked by oxygen atoms to compose the framework. In the zeolite framework, each aluminum atom introduces one negative charge on the framework which must be balanced by an exchangeable cation $\left(\mathrm{Ca}^{2+}\right.$, $\mathrm{Mg}^{2+}, \mathrm{Na}^{+}, \mathrm{K}^{+}$, etc.). The exchangeable cations located within the framework play a crucial role in adsorption and thermal properties of the zeolites. Clinoptilolite, one of the most commonly observed natural zeolite mineral, is a member of the heulandite group [1]. Its framework structure consists of three channels. The channel A and $\mathrm{B}, 10$-member and 8-member rings, respectively; are parallel to each other while the channel C, 8-member

\footnotetext{
* Corresponding author. Tel.: +902327506274; fax: +902327506196.

E-mail address: fehimeozkan@iyte.edu.tr (F. Cakicioglu-Ozkan).
}

ring, intersects the channel A and B. Strong specific interaction of the cationic sites with water vapor, due to high dipole moment of the water leads to selective adsorption of water by the zeolites. Based on this strong water-clinoptilolite interactions, several processes with different applications of water adsorption could be mentioned such as air drying [2,3], corn drying [4,5], energy storage [6,7], hydrocarbon drying [8] applications. In separation (gas or liquid) technology, the existence of water hinders the adsorption of the others since it is selectively adsorbed by various adsorbents, especially by the zeolites. On the other hand the presence of water determines the product obtained in catalytic reactions $[9,10]$.

Adsorption of small water molecule (molecular diameter: $2.66 \AA$ ) is also used to obtain information regarding the impurities in natural zeolite tuff [11] and characterize the microporous adsorbents such as microporous carbon and zeolite. The water vapor adsorption on cation exchanged natural zeolite [12,13], HZSM-5 [14] and carbon [15] have been studied in the analysis 
of the interaction mechanism between water and energetically heterogeneous surface.

The treatment of the natural zeolitic tuff with $\mathrm{HCl}$ causes the dealumination (hydrolysis of $\mathrm{Al}-\mathrm{O}-\mathrm{Si}$ bonds) besides of the exchange of the cations by hydronium ions $\left(\mathrm{H}_{3} \mathrm{O}^{+}\right)$. The study [16] of water vapor adsorption on dealuminated fuajasite showed that the change in the shape of the adsorption isotherm and the existence of correlation between the micropore volume accessible to water and the framework Si/Al ratio. Similarly, Sano et al. [17] obtained linear relationship between the number of framework aluminum of ZSM-5 zeolite and limiting pore volume estimated by water vapor adsorption. In both studies, the water molecule was used as probe molecule for understanding the dealumination degree. In the study presented hereby the aim was to prepare the $\mathrm{HCl}$ treated forms of the natural zeolitic tuff and investigate the effect of the $\mathrm{HCl}$ treatment parameters (temperature and concentration) on the water vapor adsorption properties of natural zeolite.

\section{Experimental}

The natural zeolitic tuff used in this study originated from the deposite in Bigadiç, Turkey. The major impurity in the tuff was quartz. The tuff was crushed and sieved to obtain 4-5 $\mathrm{mm}$ fractions, washed with distilled water at $25{ }^{\circ} \mathrm{C}$ to remove the water soluble impurities. This washed zeolite (CLI) was dried in a vacuum oven at $180{ }^{\circ} \mathrm{C}$ and used to prepare the acid treated forms. The chemical composition of CLI was (in oxide $\mathrm{wt} \%$ ): $\mathrm{SiO}_{2}, 71.75 ; \mathrm{Al}_{2} \mathrm{O}_{3}, 10.91 ; \mathrm{Fe}_{2} \mathrm{O}_{3}, 0.54 ; \mathrm{MgO}, 1.08$;
$\mathrm{CaO}, 2.3 ; \mathrm{Na}_{2} \mathrm{O}, 1.19 ; \mathrm{K}_{2} \mathrm{O}, 4.3 ; \mathrm{TiO}, 0.17 ; \mathrm{MnO}$, 0.0008 and $\mathrm{H}_{2} \mathrm{O}, 7.77$. This result showed that with an $\mathrm{Si} / \mathrm{Al}$ ratio of 6.22 and $(\mathrm{Na}+\mathrm{K}) \geqslant \mathrm{Ca}$, the CLI zeolite is fine within the composition range of high-silica clinoptilolite [18].

Acid treated forms were prepared by treating $5 \mathrm{~g}$ of CLI with $100 \mathrm{ml}$ of $0.032,0.16,0.32,1.6$ and $5 \mathrm{M} \mathrm{HCl}$ solutions in a shaker at $25,40,75$ and $100{ }^{\circ} \mathrm{C}$ for $3 \mathrm{~h}$. Then it was washed until no $\mathrm{Cl}^{-}$ions were detected in the washing water by using $\mathrm{AgNO}_{3}$ solution. The acid extracts were analyzed for $\mathrm{Na}, \mathrm{K}, \mathrm{Al}, \mathrm{Ca}, \mathrm{Mg}$ and $\mathrm{Fe}$ elements by using atomic absorption spectrophotometer (X Orian 10BQ).

In the characterization of the CLI and its acid treated forms, infrared and water vapor adsorption data were used. The infrared spectra of the zeolites were taken by using $\mathrm{KBr}$ pellet technique with Shimadzu IR 470 spectrometer. Water adsorption isotherms (at $25{ }^{\circ} \mathrm{C}$ ) were measured using volumetric apparatus (Omnisorp $100 \mathrm{cx})$ by static technique. Prior to isotherm acquisition, the CLI were outgassed for $16 \mathrm{~h}$ by heating at 160, 250, 400 or $600{ }^{\circ} \mathrm{C}$ under vacuum of higher than $10^{-5}$ mbar.

\section{Results and discussion}

\subsection{Acid treatment studies}

The cation content of the acid extracts was used to calculate the chemical composition of the zeolites used in this study and presented in Table 1 . The exchange degree $\left(X_{i}\right)$ of each cation $(i)$ which is the removal percent of the initial amount of the cation into zeolite was also

Table 1

Chemical composition of the acid $(\mathrm{HCl})$ treated zeolites used in this study

\begin{tabular}{|c|c|c|c|c|c|c|c|c|}
\hline \multicolumn{2}{|c|}{$\mathrm{HCl}$ treatment conditions } & \multirow[t]{2}{*}{$\% \mathrm{Al}_{2} \mathrm{O}_{3}$} & \multirow[t]{2}{*}{$\% \mathrm{Fe}_{2} \mathrm{O}_{3}$} & \multirow[t]{2}{*}{$\% \mathrm{Na}_{2} \mathrm{O}$} & \multirow[t]{2}{*}{$\% \mathrm{~K}_{2} \mathrm{O}$} & \multirow[t]{2}{*}{$\% \mathrm{CaO}$} & \multirow[t]{2}{*}{$\% \mathrm{MgO}$} & \multirow[t]{2}{*}{$\% \mathrm{SiO}_{2}$} \\
\hline Concentration (M) & Temperature $\left({ }^{\circ} \mathrm{C}\right)$ & & & & & & & \\
\hline \multirow[t]{3}{*}{0.032} & 25 & 10.81 & 0.54 & 1.15 & 4.17 & 2.15 & 1.07 & 68.90 \\
\hline & 40 & 10.70 & 0.54 & 1.15 & 4.13 & 2.07 & 1.04 & 71.20 \\
\hline & 75 & 10.70 & 0.54 & 1.12 & 4.04 & 2.12 & 1.08 & 70.50 \\
\hline \multirow[t]{4}{*}{0.16} & 25 & 10.57 & 0.53 & 1.12 & 3.99 & 2.05 & 1.04 & 70.49 \\
\hline & 40 & 10.22 & 0.54 & 1.11 & 3.95 & 1.95 & 0.98 & 71.05 \\
\hline & 75 & 10.28 & 0.52 & 1.11 & 3.77 & 1.78 & 0.86 & 72.18 \\
\hline & 100 & 9.13 & 0.48 & 1.09 & 3.67 & 1.85 & 0.88 & 73.45 \\
\hline \multirow[t]{3}{*}{0.32} & 25 & 10.43 & 0.53 & 1.13 & 3.94 & 1.99 & 1.03 & 70.20 \\
\hline & 40 & 9.88 & 0.53 & 1.12 & 3.86 & 1.76 & 0.85 & 71.64 \\
\hline & 75 & 8.72 & 0.48 & 1.10 & 3.66 & 1.59 & 0.78 & 73.63 \\
\hline \multirow[t]{4}{*}{1.6} & 25 & 10.00 & 0.53 & 1.10 & 3.73 & 1.94 & 0.88 & 70.78 \\
\hline & 40 & 9.58 & 0.52 & 1.11 & 3.73 & 1.79 & 0.92 & 71.84 \\
\hline & 75 & 8.02 & 0.30 & 1.11 & 3.54 & 1.36 & 0.59 & 74.84 \\
\hline & 100 & 6.41 & 0.26 & 1.09 & 3.38 & 1.10 & 0.83 & 74.65 \\
\hline \multirow[t]{4}{*}{5} & 25 & 9.68 & 0.51 & 1.15 & 3.85 & 2.05 & 1.01 & 71.20 \\
\hline & 40 & 9.58 & 0.50 & 1.14 & 3.78 & 1.82 & 0.90 & 70.46 \\
\hline & 75 & 4.68 & 0.31 & 1.12 & 3.66 & 1.20 & 0.23 & 78.51 \\
\hline & 100 & 2.58 & 0.05 & 1.13 & 3.56 & 0.96 & 0.15 & 79.31 \\
\hline
\end{tabular}






Fig. 1. The change in dealumination degree with $\mathrm{HCl}$ concentration.

calculated to compare the effect of the $\mathrm{HCl}$ treatment on each cation. As can be seen from Table 1, the cation content of the zeolite decreased with increasing $\mathrm{HCl}$ temperature and concentration but the removal of cation and aluminum was incomplete. The monovalent cations, such as $\mathrm{Na}^{+}$and $\mathrm{K}^{+}$ions content of the zeolite slightly changed during the acid treatment applied in this study. The exchange degree of the $\mathrm{Na}^{+}$and $\mathrm{K}^{+}$ions $\left(\mathrm{X}_{\mathrm{Na}}\right.$ and $\left.\mathrm{X}_{\mathrm{K}}\right)$, is low $(<10 \%$ and $20 \%$, respectively) for the temperatures of $25,40,75$ and $100{ }^{\circ} \mathrm{C}$ and changes a little with acid concentration. However temperature and $\mathrm{HCl}$ concentration were very effective in the removal of $\mathrm{Fe}^{3+}, \mathrm{Ca}^{2+}$ and $\mathrm{Mg}^{2+}$ cations and their exchange degrees reached to $90 \%, 57 \%$ and $85 \%$ at $100{ }^{\circ} \mathrm{C}$, respectively. Table 1 becomes also clear that the removal of silicon atom hardly takes place during acid treatment indicating the high stability of clinoptilolite rich natural zeolite in the $\mathrm{HCl}$ solution. As seen from the Fig. 1 the dealumination $\left(\mathrm{X}_{\mathrm{Al}}\right)$ gradually increased with $\mathrm{HCl}$ concentration and reached to $57 \%$ and $75 \%$ at 75 and $100{ }^{\circ} \mathrm{C}$, respectively; whereas, $\mathrm{X}_{\mathrm{Al}}$ was low $(10 \%)$ and not influenced by $\mathrm{HCl}$ concentration at 25 and $40{ }^{\circ} \mathrm{C}$.

\subsection{IR Studies}

The IR spectra (at the $400-1200 \mathrm{~cm}^{-1}$ region) of the representative acid treated zeolites are shown in Fig. 2(a) and (b). For the zeolites prepared the strong bands at 1056 and $451.2 \mathrm{~cm}^{-1}$, assigned to a $\mathrm{T}-\mathrm{O}$ asymmetric stretching and $\mathrm{T}-\mathrm{O}$ bending vibrations of the internal tetrahedra, respectively, and the weak bands at 790 and $604.8 \mathrm{~cm}^{-1}$ wave numbers assigned to external symmetric stretching and double ring vibrations, respectively, were observed.

The effect of dealumination was observed with the shift in the wave numbers of the IR bands. Fig. 2(a) shows the change in the spectrum with the $\mathrm{HCl}$ concentration at $75^{\circ} \mathrm{C}$. As seen from the figure the position of the vibrations at $1056 \mathrm{~cm}^{-1}$ (the asymmetric stretching mode involving mainly the tetrahedral atoms) is very
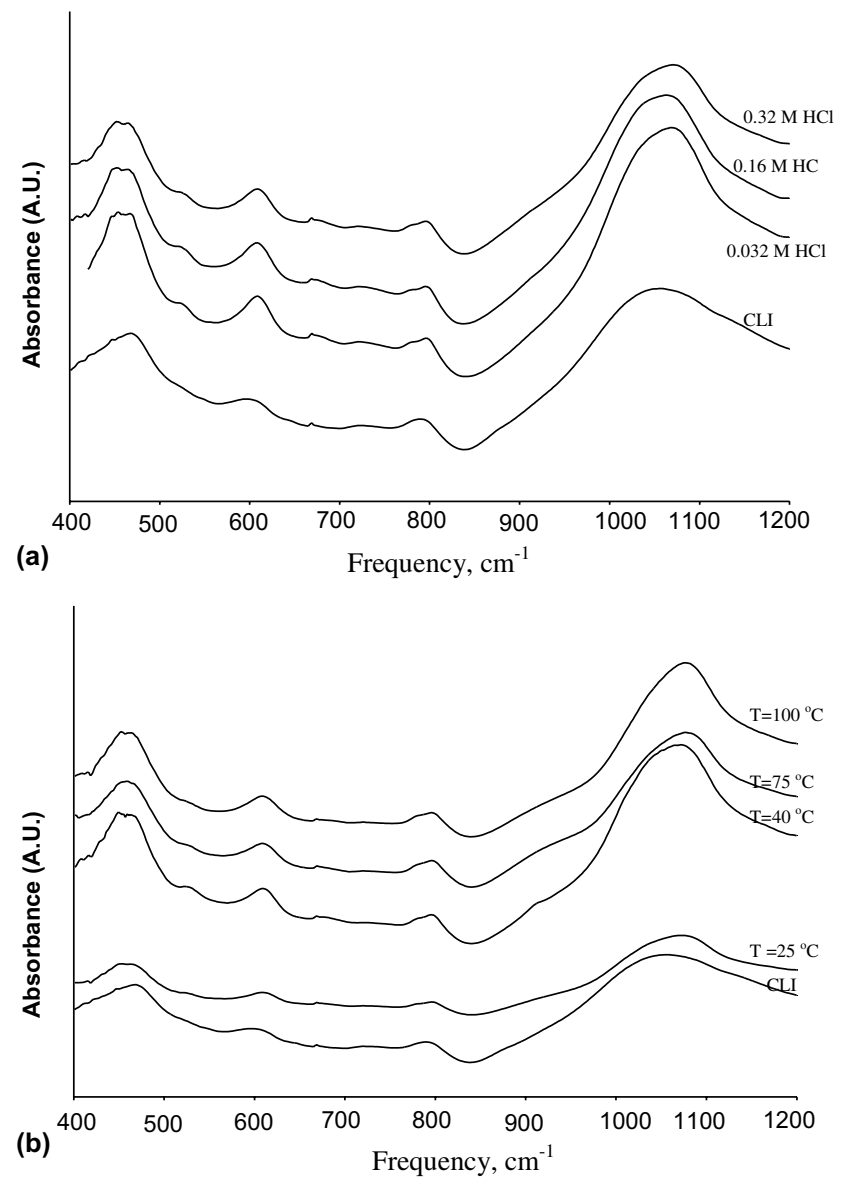

Fig. 2. (a) Infrared spectra of CLI and acid treated natural zeolite at $75^{\circ} \mathrm{C}$. (b) Infrared spectra of CLI and acid treated natural zeolite with $1.6 \mathrm{HCl}$ solutions.

sensitive to the dealumination degree and this zeolitic band shifted to $1080 \mathrm{~cm}^{-1}$ as the dealumination degree increased from $20.1 \%$ to $57.1 \%$ depending on the increase in $\mathrm{HCl}$ concentration from 0.032 to $0.32 \mathrm{M}$. Similarly the effect of acid treatment temperature on the $\mathrm{HCl}$ concentration of $1.6 \mathrm{M}$ can clearly seen from the Fig. 2(b) as shift in the position of the vibration at $1056 \mathrm{~cm}^{-1}$ to $1081 \mathrm{~cm}^{-1}$ with increase in the dealumination degree from $8.3 \%$ to $39.4 \%$ with increasing temperature from 25 to $100{ }^{\circ} \mathrm{C}$. The shifting of the $1056 \mathrm{~cm}^{-1}$ wave number of $\mathrm{T}-\mathrm{O}-\mathrm{T}$ bond to the higher values is attributed to the dealumination of zeolite framework and the change in the bond strength and $\mathrm{Si}-\mathrm{O}-\mathrm{Si}$ angle [19].

\subsection{Adsorption studies}

Fig. 3 shows the effect of outgasing temperature on the water vapour adsorption isotherms for CLI. The gradual increase in the amount adsorbed was observed for the zeolites outgassed up to $400{ }^{\circ} \mathrm{C}$. As the outgassing temperature further increased, the amount of water vapor adsorbed by the zeolite decreased owing to 


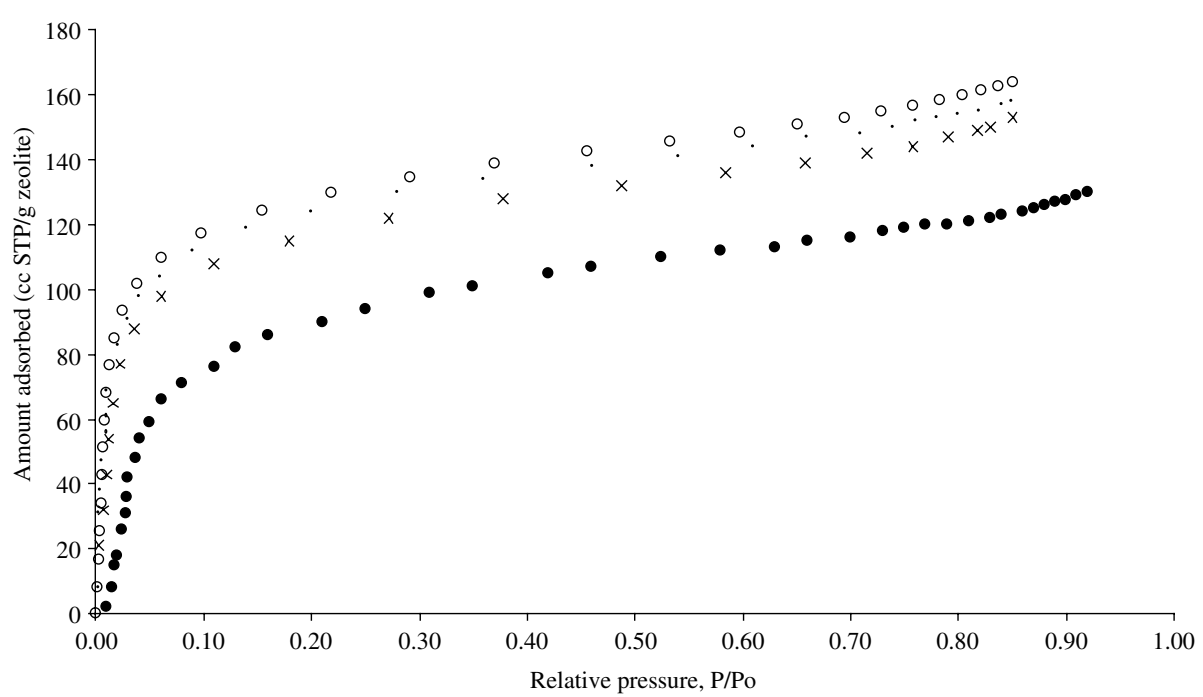

Fig. 3. Water vapor adsorption isotherm of the CLI outgassed at $160^{\circ} \mathrm{C}(\times), 250{ }^{\circ} \mathrm{C}(\cdot), 400{ }^{\circ} \mathrm{C}(\mathrm{O})$ and $600{ }^{\circ} \mathrm{C}$

collapse of the framework. Therefore, the outgasing of CLI and acid treated zeolites was performed at 400 ${ }^{\circ} \mathrm{C}$. The water vapour adsorption isotherms of the CLI zeolite and its representative acid treated forms are given in the Fig. 4. The isotherms are of type 1. However a slight increase in adsorption at high relative pressure was observed relating the presence of the impurity or
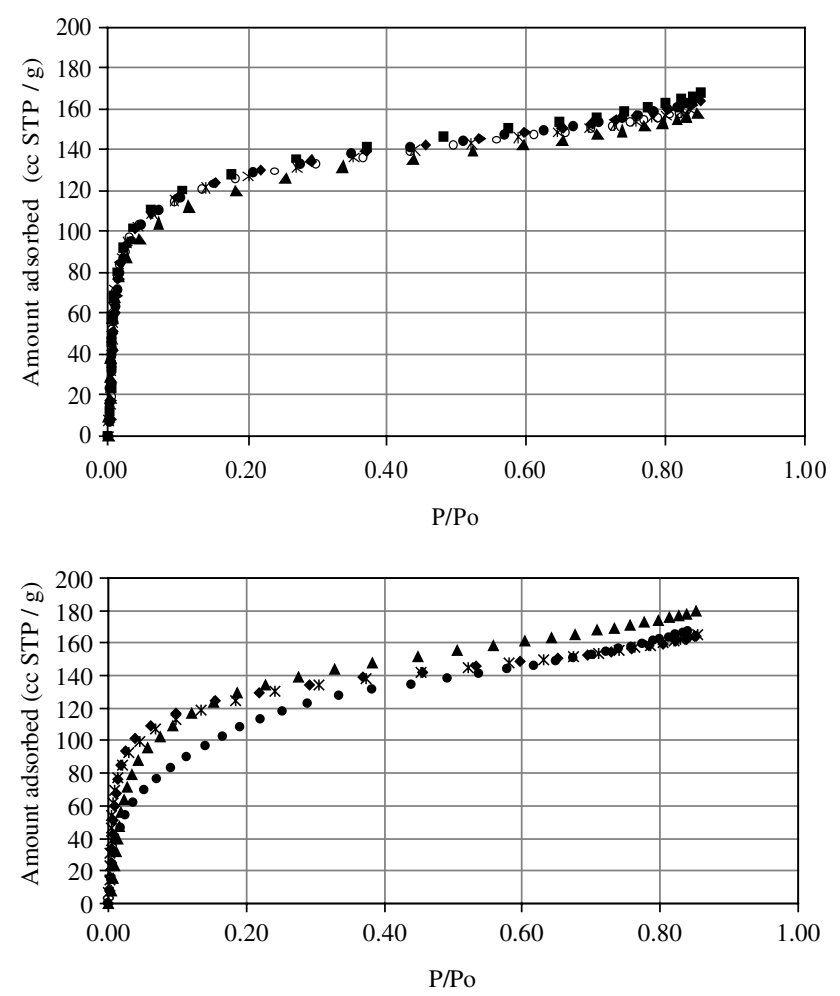

Fig. 4. Water vapor adsorption isotherm of the CLI ( $)$ and its acid treated forms at $25^{\circ} \mathrm{C}$ (upper) and $100{ }^{\circ} \mathrm{C}$ (lower). $\mathrm{HCl}$ Concentrations (M): (O) 0.032; (*) 0.16; (ロ) $0.32 ;(\boldsymbol{\Delta}) 1.6 ;(\bullet) 5$. extraframework formation on the crystal surface as expected for natural zeolites [20]. The isotherms are very similar for the zeolites treated at $25^{\circ} \mathrm{C}$. However the adsorption at the zeolites treated at $100{ }^{\circ} \mathrm{C}$ diminished as a result of decrease in polar nature of the zeolite crystal.

The surface area of the zeolites was determined by using BET and Langmuir equations from isotherm data and presented in the Table 2. Although the Langmuir surface area is more commonly reported for monolayer adsorption on microporous solids, BET method was also used for understanding the strength of interaction between zeolite surface and water vapor. Surface areas are lower when calculated with the BET equation, indicating that the formation of second adsorption layer may occur before the surface could be covered completely by the adsorbate, since the desorption occurs depending on the high amount of heat which has evolved during water vapor adsorption. This can also be understood from the high BET $\mathrm{C}$ values calculated (Table 2). BET $\mathrm{C}$ values are related to the strength of $\mathrm{H}_{2} \mathrm{O}$-adsorbent interactions and the positive values indicating the enthalpy of first adsorbed layer was higher than the latent heat of water vapor. As seen from Table 2, the BET $\mathrm{C}$ values are very high meaning that monolayer is instantly formed and multilayering starts immediately.

The Dubinin-Raduschevich curve $\left(\operatorname{Ln} W\right.$ vs $\operatorname{Ln}\left(P_{0} /\right.$ $P)^{2}$ ) is plotted with experimental data in the range of relative pressure up to around 0.1 and presented in Fig. 5 . As seen from the figure the Dubinin-Raduschevich (DR) plots presents two linear parts. The first one, in the low relative pressure range (high $\operatorname{Ln}\left(P_{0} / P\right)^{2}$ ), corresponds to the adsorption of water on specific sites (balancing cation) in narrow pores (ultra-micro pores) and the second one, in the high relative pressure range 
Table 2

Water vapour adsorption properties of the acid treated clinoptilolite rich tuff

\begin{tabular}{|c|c|c|c|c|c|c|c|c|}
\hline $\begin{array}{l}\text { Temperature } \\
\left({ }^{\circ} \mathrm{C}\right)\end{array}$ & $\begin{array}{l}\mathrm{HCl} \\
\text { concentration } \\
\text { (M) }\end{array}$ & $\begin{array}{l}A_{\mathrm{L}} \\
\left(\mathrm{m}^{2} / \mathrm{g}\right)\end{array}$ & $\begin{array}{l}A_{\mathrm{BET}} \\
\left(\mathrm{m}^{2} / \mathrm{g}\right)\end{array}$ & $C$ & $\begin{array}{l}W_{01} \\
(\mathrm{cc} / \mathrm{g})\end{array}$ & $\begin{array}{l}W_{02} \\
(\mathrm{cc} / \mathrm{g})\end{array}$ & $\begin{array}{l}W_{0} \\
(\mathrm{cc} / \mathrm{g})\end{array}$ & $\begin{array}{l}V_{\max } \\
(\mathrm{cc} / \mathrm{g})\end{array}$ \\
\hline CLI & & 384 & 299 & 684 & 0.0570 & 0.065 & 0.122 & 0.13 \\
\hline 25 & $\begin{array}{l}0.032 \\
0.16 \\
0.32 \\
1.6 \\
5\end{array}$ & $\begin{array}{l}384 \\
381 \\
388 \\
370 \\
388\end{array}$ & $\begin{array}{l}298 \\
298 \\
297 \\
279 \\
279\end{array}$ & $\begin{array}{r}431 \\
496 \\
6907 \\
856 \\
519\end{array}$ & $\begin{array}{l}0.060 \\
0.054 \\
0.058 \\
0.040 \\
0.053\end{array}$ & $\begin{array}{l}0.063 \\
0.067 \\
0.065 \\
0.070 \\
0.069\end{array}$ & $\begin{array}{l}0.122 \\
0.120 \\
0.122 \\
0.111 \\
0.112\end{array}$ & $\begin{array}{l}0.13 \\
0.13 \\
0.14 \\
0.14 \\
0.14\end{array}$ \\
\hline 40 & $\begin{array}{l}0.032 \\
0.16 \\
0.32 \\
1.6 \\
5\end{array}$ & $\begin{array}{l}361 \\
359 \\
369 \\
359 \\
402\end{array}$ & $\begin{array}{l}271 \\
260 \\
293 \\
280 \\
326\end{array}$ & $\begin{array}{r}360 \\
1828 \\
2007 \\
117 \\
110\end{array}$ & $\begin{array}{l}0.052 \\
0.050 \\
0.050 \\
0.050 \\
0.062\end{array}$ & $\begin{array}{l}0.058 \\
0.057 \\
0.056 \\
0.073 \\
0.067\end{array}$ & $\begin{array}{l}0.111 \\
0.106 \\
0.106 \\
0.122 \\
0.128\end{array}$ & $\begin{array}{l}0.13 \\
0.12 \\
0.13 \\
0.13 \\
0.13\end{array}$ \\
\hline 75 & $\begin{array}{l}0.032 \\
0.16 \\
0.32 \\
1.6 \\
5\end{array}$ & $\begin{array}{l}362 \\
410 \\
372 \\
350 \\
197\end{array}$ & $\begin{array}{l}279 \\
317 \\
297 \\
287 \\
239\end{array}$ & $\begin{array}{r}567 \\
96 \\
106 \\
52 \\
31\end{array}$ & $\begin{array}{l}0.050 \\
0.059 \\
0.044 \\
0.049 \\
0.023\end{array}$ & $\begin{array}{l}0.049 \\
0.061 \\
0.060 \\
0.052 \\
0.054\end{array}$ & $\begin{array}{l}0.099 \\
0.199 \\
0.104 \\
0.101 \\
0.077\end{array}$ & $\begin{array}{l}0.12 \\
0.14 \\
0.13 \\
0.13 \\
0.11\end{array}$ \\
\hline 100 & $\begin{array}{l}0.16 \\
1.6 \\
5\end{array}$ & $\begin{array}{l}383 \\
395 \\
306\end{array}$ & $\begin{array}{l}298 \\
319 \\
273\end{array}$ & $\begin{array}{r}327 \\
65 \\
37\end{array}$ & $\begin{array}{l}0.045 \\
0.054 \\
0.026\end{array}$ & $\begin{array}{l}0.059 \\
0.059 \\
0.063\end{array}$ & $\begin{array}{l}0.104 \\
0.116 \\
0.089\end{array}$ & $\begin{array}{l}0.13 \\
0.15 \\
0.14\end{array}$ \\
\hline
\end{tabular}


Fig. 5. Dubinin-Raduschevich plots of the CLI and its acid treated forms at $25^{\circ} \mathrm{C}$ (upper) and $100{ }^{\circ} \mathrm{C}$ (lower). 


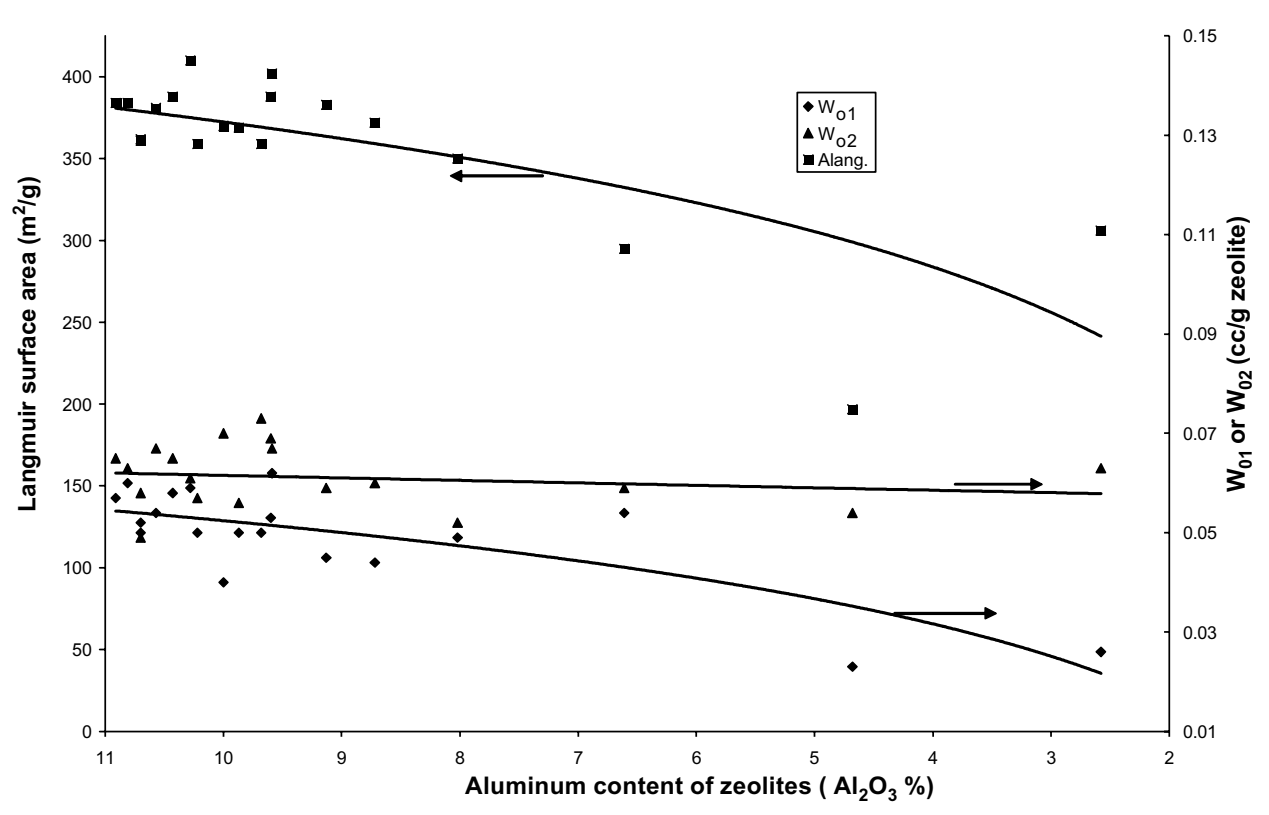

Fig. 6. The change in the specific surface area and the micropore volumes with aluminum content of zeolite.

(low $\operatorname{Ln}\left(P_{0} / P\right)^{2}$ ), related to filling of wide pores (supermicropores) with non-specific sites under the effect of dispersion interactions. For that reason, in the analyses of the D-R plots the two-term Dubinin-Radushkevich equation [21],

$$
\begin{aligned}
W= & W_{01} \exp \left(-\left(\frac{R T}{E_{1}}\left(\operatorname{Ln}\left(P_{0} / P\right)\right)\right)^{2}\right) \\
& +W_{02} \exp \left(-\left(\frac{R T}{E_{2}}\left(\operatorname{Ln}\left(P_{0} / P\right)\right)\right)^{2}\right)
\end{aligned}
$$

was used, where $W$ is the amount adsorbed $(\mathrm{cc} / \mathrm{g})$ at relative pressure $\left(P / P_{0}\right)$ and $E_{1}$ and $E_{2}$ are characteristic energy of adsorption in ultra-micropore and supermicropore, respectively. $R$ is gas constant and $T$ is adsorption temperature. Adsorption characteristic energy can be calculated from the slope of the D-R plots. As seen from Fig. 5, in the high relative pressure (low $\left.\operatorname{Ln}\left(P_{0} / P^{2}\right)\right)$ range the $\mathrm{D}-\mathrm{R}$ plots have almost similar trends but are scattered in low relative pressure range (high $\operatorname{Ln}\left(P_{0} / P^{2}\right)$ ) at $25{ }^{\circ} \mathrm{C} \mathrm{HCl}$ treatment. This shows that $\mathrm{HCl}$ treatment altered only the adsorption mechanism in ultra-micropores. However the adsorption mechanism in super and ultra-micropore was influenced by the $\mathrm{HCl}$ treatment at $100{ }^{\circ} \mathrm{C}$. On the other hand, the extrapolation to $\operatorname{Ln}\left(P_{0} / P\right)^{2}=0$ of D-R plots leads to the determination of the specific total micropore volume, $W_{0}$. The volume at the intersection of the two linear lines (at about 0.06 of relative pressure) is used to calculate ultra-micropore volume, $W_{01}$. The super-micropore volume, $W_{02}$ was obtained by subtracting of $W_{01}$ from $W_{0}$ and presented in Table 2. As seen from the table, the ultra-micropore volumes, $W_{01}$ are influenced by the acid treatment depending on $\mathrm{HCl}$ temperature and concentration. However $W_{02}$ values of the zeolites practically did not change (ca. $0.06 \mathrm{cc} / \mathrm{g}$ ) during the acid treatment. Similarly the maximum adsorption capacity, $V_{\max }$ (amount adsorbed at $P / P_{0}=0.85$ ) at adsorption temperature, $25{ }^{\circ} \mathrm{C}$ did not significantly change. The effect of the acid treatment can be explained with the change in the $\mathrm{Al}_{2} \mathrm{O}_{3}$ content of zeolite. Fig. 6 shows the change in Langmuir surface area, $A_{\mathrm{L}}$ and micropore volumes with the aluminum content (as $\mathrm{Al}_{2} \mathrm{O}_{3} \%$ ) of zeolite. The surface area, $A_{\mathrm{L}}$ and ultra micropore volume, $W_{01}$ did not significantly change when aluminum content was higher than $8 \%$ (i.e., dealumination degree was $40 \%$ ). Further dealumination was reflected as decrease in $A_{\mathrm{L}}$ and $W_{01}$. For example the zeolites treated with $5 \mathrm{M} \mathrm{HCl}$ at 75 and $100{ }^{\circ} \mathrm{C}$, which have $57.1 \%$ and $76.1 \%$ dealumination degree, respectively, have the smallest $W_{01}$ values, ca. $0.025 \mathrm{cc} / \mathrm{g}$. This decrease may be due to the removal of aluminum from the framework.

\section{Conclusion}

This study in which the effect of acid $(\mathrm{HCl})$ treatment on the water vapor adsorption properties of clinoptilolite rich zeolitic tuff was investigated, concentration and temperature of $\mathrm{HCl}$ solution were not effective in the removal of monovalent cation such as $\mathrm{Na}$ and $\mathrm{K}$. However, the increase of both temperature and concentration caused an increase in the removal of univalent cations such as $\mathrm{Mg}, \mathrm{Fe}$ and $\mathrm{Ca}$. Removal of the aluminum was very sensitive to $\mathrm{HCl}$ solution concentration at high treatment temperature. During this removal 
the super-micropore volume did not significantly change (about $0.06 \mathrm{cc} / \mathrm{g}$ ). The ultra-micropore volume and the Langmuir surface area decreased approximately to $0.026 \mathrm{cc} / \mathrm{g}$ and $300 \mathrm{~m}^{2} / \mathrm{g}$ when dealumination degree reached to $\geqslant 40 \%$. This can be explained with the removal of framework aluminum with the above percent where the specific interaction was dominant.

\section{References}

[1] D.W. Breck, Zeolites: Molecular Sieves, Wiley-Interscience, New York, 1980.

[2] S. Ulku, D. Balkose, H. Baltacıoglu, F. Ozkan, A. Yıldırım, Drying Technol. 10 (2) (1992) 475.

[3] S. Ulku, Z. Kıvrak, M. Mobedi, in: A.S. Mujundar (Ed.), Drying 86, Hemisphere Publishing Corporation, Washington, 1986, p. 807.

[4] S. Ulku, F. Ozkan (Cakıcıglu), Renew. Energy 1 (5-6) (1991) 695.

[5] S. Ulku, G. Uckan, in: A.S. Mujundar (Ed.), Drying 86, Hemisphere Publishing Corporation, Washington, 1986, p. 531.
[6] S. Ulku, J. Heat Recov. Syst. 6 (4) (1986) 277.

[7] S. Ulku, M. Mobedi, in: B. Kılkıs, S. Kakac (Eds.), Energy Storage Systems, Nato ASI series E: 167, Kluwer Academic Publishers, London, 1989, pp. 487-507.

[8] F. Turgut, S. Ulku, Separ. Sci. Technol. 31 (20) (1996) 2855.

[9] M. Shimokawabe, S. Ono, S. Sasaki, N. Takezawa, Appl. Surf. Sci. 121/122 (1997) 400

[10] F. Ozkan, G. Gunduz, O. Akpolat, N. Buşun, Dmitry Yu Murzin, Chem. Eng. J. 91 (2003) 257.

[11] S. Yamaka, P.B. Malla, S. Komarnani, Zeolites 9 (1989) 18.

[12] F. Ozkan, S. Ulku, Adsorpt. Sci. Technol. 21 (4) (2003) 309.

[13] D.A. White, R.L. Bussey, Separ. Purif. Technol. 11 (1997) 137.

[14] D.H. Olson, W.O. Haag, W.S. Borghard, Micropor. Mesopor. Mater. 35/36 (2000) 435

[15] P. Lodewyckx, E.F. Vansant, Carbon 37 (1999) 1647.

[16] M. Simonot-Grange, A. Chaouri, G. Weber, P. Dufresne, P.F. Raatz, J. Joly, Zeolites 12 (1992) 155.

[17] T. Sano, N. Yamanhita, Y. Iwami, K. Takeda, Y. Kawakami, Zeolites 16 (1996) 258.

[18] A. Allietti, Am. Miner. 57 (1972) 1448.

[19] J.M. Man, S. Uede, M.J. Annen, M.E. Davis, R.A. Santen, Zeolites 12 (1992) 789.

[20] S. Yamanaka, P.B. Malla, S. Komarneni, Zeolites 9 (1989) 18.

[21] T.I. Izotova, M.M. Dubinin, Zh. Fiz. Khim. 39 (1965) 2796. 